\title{
Inhibition of Inflammatory Cytokine Secretion by Plant-Derived Compounds Inuviscolide and Tomentosin: The Role of NFKB and STAT1
}

\author{
Galya Abrham ${ }^{1}$, Sara Dovrat ${ }^{2}$, Hanna Bessler ${ }^{3}$, Shlomo Grossman ${ }^{*}, 1$, Uri Nir ${ }^{1}$ and Margalit Bergman ${ }^{1}$ \\ ${ }^{I}$ The Mina and Everard Goodman Faculty of Life-Sciences, Bar-Ilan University, Ramat-Gan 52900, Israel \\ ${ }^{2}$ The Open University of Israel, Tel Aviv, Israel \\ ${ }^{3}$ Rabin Medical Center - Hasharon Hospital, Petah Tikva, Israel
}

\begin{abstract}
The plant Inula viscosa has been shown to possess many important medicinal benefits, including anti-inflammatory, anti-oxidant, anti-bacterial, and anti-fungal activities, but the plant metabolites that mediate these effects and their mechanism of action are poorly understood. In a previous study, we demonstrated a reduced expression of the p65 subunit of nuclear factor kappa B $(\mathrm{NF} K \mathrm{~B})$ in melanoma cells treated with the purified sesquiterpene lactone compounds, Inuviscolide (Inv) and Tomentosin (Tom), extracted from Inula viscosa leaves. In this study, we tested the invitro effect of these purified compounds on the secretion of pro-inflammatory cytokines from human peripheral blood mononuclear cells (PBMCs) upon stimulation with lipopolysaccharide (LPS) or phorbol myristate acetate (PMA). Their possible mechanism of action was also studied. The results showed that both agents caused decreased production of IL-2, IL-1 $\beta$, IFN $\gamma$, and slightly increased secretion of TNF $\alpha$, whereas secretion of IL-6 was not affected. The elevated levels of TNFa did not appear to affect the viability of human PBMCs. Western blot analysis revealed a reduction in the protein level of both the transcription factor component p65/RelA of nuclear factor- $\mathrm{kB}(\mathrm{NF} \kappa \mathrm{B})$ and the signal transducer and activator of transcription 1 (STAT1) through proteosomal degradation. However, no change was observed in the expression level of the nuclear factor- $\mathrm{KB}$ component, $\mathrm{p} 50$ (NFKB), or the signal transducer and activator of transcription 3 (STAT3). Taken together, our results indicate the possible future use of these agents as an anti-inflammatory treatment in cases where overstimulation of cytokine secretion is the basis for the pathological symptoms.
\end{abstract}

Keywords: Inula viscosa, IL-2, IL-1 $\beta$, IFN $\gamma$, inflammation.

\section{INTRODUCTION}

Inula viscosa (Compositae) has been regarded as one of the most important medicinal plants around the Mediterranean Basin, and its anti-inflammatory activity has been widely reported [1]. Secondary metabolites isolated from leaf extracts were found to inhibit inflammation both in vitro and in vivo [2]. Recently, two natural diterpenes originating from another family member called Egletes viscosa were shown to possess anti-dermatitis activity in an experimental mouse model [3]. Several studies have shed light upon the possible mechanism for this activity by showing that plant extract could inhibit the activity of both COX 1 [4], COX 2 and iNOS [5]. COX2, a key enzyme in archidonic acid metabolism that leads to the production of pro-inflammatory prostaglandins $[2,6]$. In a previous study, we purified sesquiterpene lactones derived from Inula viscosa leaves and evaluated their anti-cancer activity against melanoma and prostate cancer cells $[7,8]$. Interestingly, we found that the purified compounds Tomentosin (Tom) and Inuviscolide (Inv) reduced the expression of $\mathrm{p} 65 / \mathrm{Rel} \mathrm{A}$, a component of the transcription factor $\mathrm{NF \kappa B}$, in a dose-

*Address correspondence to this author at the Mina and Everard Goodman Faculty of Life-Sciences, Bar-Ilan University, Ramat-Gan 52900, Israel; Tel: 972-3-5318050; Fax: 972-3-7384058;

E-mail: bergmam@mail.biu.ac.il dependent manner [7]. Since NFKB is a master regulator of immune responses, including pro-inflammatory cytokine production [9], we were interested in exploring the possibility that downregulation of $\mathrm{NF} \kappa \mathrm{B}$ participates in the anti-inflammatory activities of these plant extracts, as well. We adapted a model of normal human peripheral blood mononuclear cells (PBMCs) stimulated by lipopolysaccharide (LPS) or phorbol myristate acetate (PMA) and measured pro-inflammatory cytokine production by ELISA assay. Indeed, the secretion of several pro-inflammatory cytokines was reduced. To further characterize the mechanism by which these two compounds reduce cytokine secretion, we analyzed the protein level of two transcription factors closely involved with cytokine production, $\mathrm{NF \kappa B}$ and STAT1, by Western blot analysis. We demonstrated that reduction of these two proteins in the presence of Inv and Tom occurred through enhanced proteosomal degradation. The addition of either Inuviscolide or Tomentosin to LPS- or PMA-stimulated PBMC has been shown to reduce cytokine secretion. Furthermore, both compounds reduced the expression of two key proteins that play a pivotal role in the regulation of cytokine production. In summary, this investigation demonstrates that both agents have an antiinflammatory effect and sheds light upon their mechanism of action. 


\section{MATERIALS AND METHODOLOGY}

\section{Effect of Inuviscolide and Tomentosin on Cytokine Production}

\section{Extraction and Isolation Procedure}

The extraction and isolation of Inuviscolide and Tomentosin were performed as described [7].

\section{Cell Preparation}

Peripheral blood mononuclear cells (PBMCs) were separated from venous blood of healthy blood-bank donors by Histopaque-1077 (Sigma, Israel) gradient centrifugation. The cells were washed twice in phosphate-buffered saline (PBS) and suspended in a RPMI-1640 medium (Biological Industries, Beit Haemek, Israel) containing 1\% penicillin, streptomycin, nystatin, and $10 \%$ fetal calf serum (FCS) (designated as complete medium (CM)).

\section{Incubation Conditions}

PBMCs $\left(2 \times 10^{6}\right)$ were suspended in $1 \mathrm{ml}$ of complete medium. For the induction of IL1- $\beta$, IFN $\gamma$, IL-6, and TNF $\alpha$, the cultures were incubated for $24 \mathrm{~h}$ with $20 \mathrm{ng} / \mathrm{ml}$ of lipopolysaccharide (Lipopoplysacharide $W$ E. coli 055:B5, Sigma), while for the induction of IL-2, $1 \mu \mathrm{g} / \mathrm{ml}$ phorbol myristate acetate (PMA) (Sigma) and $0.5 \mu \mathrm{g} / \mathrm{ml}$ ionomycin (Sigma) were added for $48 \mathrm{~h}$. After the addition of LPS or PMA, the two compounds, Inuviscolide or Tomentosin, were added at final concentrations of 0.9 or $1.8 \mu \mathrm{M}$ for $24 \mathrm{~h}$. At the end of the incubation period, the cells were removed by centrifugation at $1500 \mathrm{rpm}$ for $10 \mathrm{~min}$; the supernatants were collected and kept at $-80^{\circ} \mathrm{C}$ until assayed for cytokine content.

\section{Cytokine Content in the Supernatants}

The concentration of the following cytokines: TNF $\alpha$, IL$1 \beta$, IL-6, IL-2, and IFN $\gamma$ in the supernatants, was tested using ELISA kits specific for human cytokines (Biosource International, Camarillo, CA), as detailed in the manufacturer's instructions. The detection thresholds of these kits were: $15 \mathrm{pg} / \mathrm{ml}$ for IL- 6 and $30 \mathrm{pg} / \mathrm{ml}$ for all the others. The $\mathrm{EC}_{50}$ of the three cytokines: IL-1 $\beta$, IL-2, and IFN $\gamma$ was calculated as described: PBMCs were incubated for $24 \mathrm{~h}$ with Inuviscolide or Tomentosin at several concentrations: $0.45,0.9,1.8,3.8,5.4$ and $10.8 \mu \mathrm{M}$, in parallel, with $20 \mathrm{ng} / \mathrm{ml}$ LPS for the induction of IL-1 $\beta$ and IFN $\gamma$, or with $1 \mu \mathrm{g} / \mathrm{ml}$ phorbol myristate acetate (PMA) and $0.5 \mu \mathrm{g} / \mathrm{ml}$ ionomycin for IL2 induction. The cytokine secretion levels were assayed in the supernatants by ELISA and were compared relatively to the positive control (PBMC+LPS) that was considered as $100 \%$ cytokine secretion. The $\mathrm{EC}_{50}$ was expressed as the concentration of each compound necessary to give a $50 \%$ reduction in the cytokine secretion.

\section{Western Blot Analysis}

For the determination of NFKB and STAT1, the cells were incubated as described above, while for the determination of proteosomal degradation, MG-132 (Alexis, Lausen, Switzerland) was added to the cells at a final concentration of $3 \mu \mathrm{M}$ for the last $4 \mathrm{~h}$ of incubation. The same amount of Dimethyl Sulfoxide (DMSO) was added to the samples as a control. At the end of the incubation period, cells were collected, whole cell proteins were extracted in lysis buffer [20 mM Tris, $\mathrm{pH} 7.5,150 \mathrm{mM} \mathrm{NaCl}, 1 \mathrm{mM}$ EDTA, $1 \%$ Nonidet P-40, $0.5 \%$ sodium deoxycholate, $2 \mathrm{mM}$ $\mathrm{Na}_{2} \mathrm{VO}_{4}, 1 \mathrm{mM}$ Natriumfluoride (Naf), $10 \mathrm{mM} \quad \beta-$ glycerophosphate] with complete mini-protease inhibitor (Roche), and rotated for $15 \mathrm{~min}$ at $4^{\circ} \mathrm{C}$. The proteins were cleared by centrifugation at $14,000 \mathrm{x} \mathrm{g}$ for $5 \mathrm{~min}$ at $4^{\circ} \mathrm{C}$. Soluble protein concentration was determined by Bradford analysis. For western blot analysis, $30 \mu \mathrm{g}$ of protein from each sample was resolved by $10 \%$ SDS-PAGE. Electroblotted proteins were detected using polyclonal antiactin antibodies (Santa Cruz Biotechnology Inc, CA, USA), polyclonal anti-NFKB p65 (sc-109, Santa Cruz Biotechnology Inc, CA, USA), polyclonal anti-NFкB p50 (c19, Delta Laboratories, Somersby, Australia), polyclonal anti-STAT1 (Cell Signaling Technology, Inc., MA), monoclonal anti-STAT3 (Transduction Laboratories, Inc., Lexington, KY), polyclonal anti-E2F1 (Santa Cruz Biotechnology Inc, CA, USA), and monoclonal anti-p53 (Cell Signaling Technology, Inc, MA). Immuno-absorbed antibodies were visualized using the chemiluminescence reaction (Pierce Chemical Co., Rockford, IL). The blots were scanned using an optical scanner - Canon Scan N670U, and the optical density of each band was determined using the ImageJ software application. For quantification, the control of each experiment was set to $100 \%$ after normalization to actin level, and the results were calculated accordingly. Results represent the means \pm standard deviation of three separate experiments.

\section{Quantification of Viable Cells (XTT)}

Quantification of viable cells was performed according to the manufacturer's instructions using the XTT cell proliferation kit (Biological Industries, Beit-Haemek Ltd, Israel). PBMC cells were plated in 96-well plates at $2 \times 10^{6}$ in $100 \mu \mathrm{l}$ medium in the presence of three concentrations of either Inv or Tom. Cell viability was determined $24 \mathrm{hr}$ after plating by measuring absorbance at a wavelength of $450 \mathrm{~nm}$. In order to measure reference absorbance (to measure nonspecific readings), the wavelength of $620 \mathrm{~nm}$ was used, as well. The absorbance was read by microplate spectrophotometer (ELISA reader).

\section{Statistics}

Data were analyzed using two tailed, paired t-test to compare between the various combinations. A $p$-value of $p<0.05$ was considered to be significant. The results are expressed as mean \pm SEM.

\section{RESULTS}

\section{Downregulation of Several Pro-inflammatory Cytokines by Inuviscolide and Tomentosin}

The inflammatory response plays an important role not only in the normal physiology but also in pathology when inflammation is recognized as a major driving force leading to development of malignancy such as cancer. Medicinal plants and their products have been used for many centuries to treat different kinds of acute and chronic inflammatory diseases like wound healing, edema and rheumatoid arthritis [10]. In a previous study, we demonstrated the effect of 
purified Inuviscolide and Tomentosin originating from Inula viscosa leaf extract (see structures, Fig. 1) on melanoma cells, showing anti-cancer activity [7]. These two compounds purified from IV water extract. The compounds were separated using TLC and their structures were determined by NMR spectroscopy, as described [7]. The isolated compounds were identified as the SLs Tomentosin and Inuviscolide (Fig. 1). In this study we have tested different combinations of these two compounds, but the results showed no synergistic effect, but only additive effect. Furthermore, we also demonstrated that Inuviscolide downregulates the expression of the $\mathrm{NF} \kappa \mathrm{B}$ component, p65/Rel A [7]. Since p65/Rel plays a major role in cytokine production [9] and in light of our previous results and the many reports of anti-inflammatory activities attributed to Inula viscosa [1], we were interested in studying the effect of these molecules in an inflammation model. Inflammation is mediated by cytokines released from peripheral blood mononuclear cells (PBMCs) in response to insults such as microbial infection, viruses, and various drugs [11-13]. This situation can be mimicked by incubating PBMCs with bacterial lipopolysaccharide (LPS), a major structural component of the outer wall of gram-negative bacteria, and considered to be a potent initiator of inflammatory responses [14]. In this study, we incubated PBMCs with LPS with or without two concentrations of the two purified compounds for $24 \mathrm{~h}$ and measured various cytokines by ELISA assay (Figs. 2, 3). We chose an incubation time of $24 \mathrm{~h}$ for several reasons: first, to enable sufficient levels of secreted cytokines to accumulate in the cell medium. Secondly, Based on the literature, $24-48 \mathrm{~h}$ is the optimal time point to obtain a significant effect in cytokine reduction compared to positive controls (cells induced by LPS) $[15,16]$, and third, because our compounds are small molecules that can enter and exit the cells freely and thereby their effect could be seen after a relatively short period of time. Both agents reduced the secretion of the pro-inflammatory cytokines IL-1 $\beta$, IL-2, and IFN $\gamma$ in a dose-dependent manner. The maximal reductions ranged between $67 \%$ and $72 \%, 82 \%$ and $84 \%$, $38 \%$ and $45 \%$, for IL- $1 \beta$, IL-2, and IFN $\gamma$, respectively (Fig. 2). IL-1 $\beta$ is considered to be a cascade inducer of inflammatory mediators, and therefore, causes augmentation

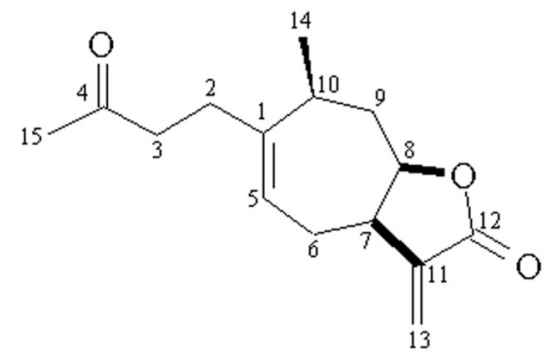

Tomentosin

\section{Inuviscolide}

Fig. (1). Chemical structure of Inuviscolide and Tomentosin.
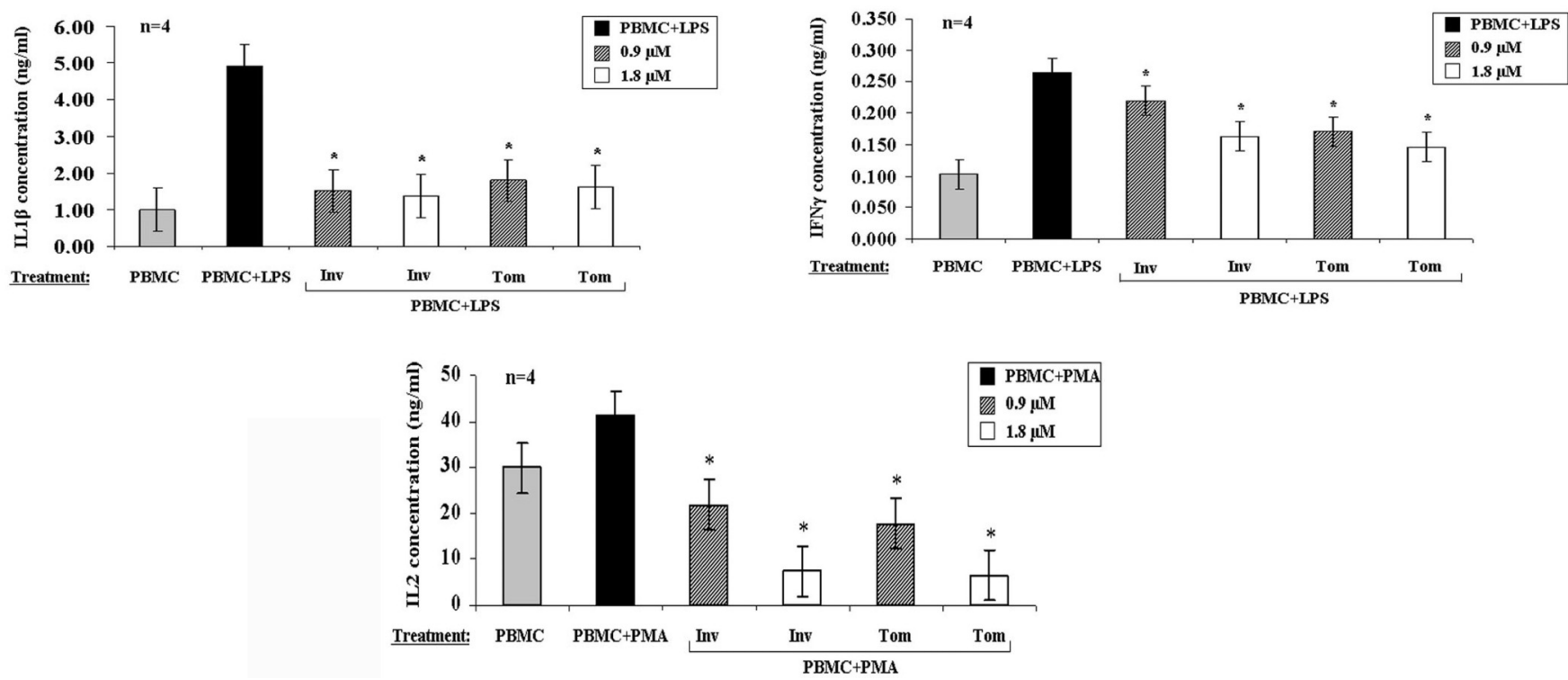

Fig. (2). Effect of Inuviscolide and Tomentosin on IL1ß, IFN $\gamma$, and IL2 secretion levels by human PBMCs in the presence of LPS. PBMCs were incubated for $24 \mathrm{~h}$ with Inuviscolide and Tomentosin together, with $20 \mathrm{ng} / \mathrm{ml} \mathrm{LPS}$ for the induction of IL-1 $\beta$ and IFN $\gamma$, or with $1 \mu \mathrm{g} / \mathrm{ml}$ phorbol myristate acetate (PMA) and $0.5 \mu \mathrm{g} / \mathrm{ml}$ ionomycin for IL2 induction. The relative cytokine secretion levels were assayed in the supernatants by ELISA. Significance of results was determined using the Student's t test: $* P<0.05$ when compared with that of the control: PBMC+LPS $(n=4)$. 
of inflammatory episodes $[17,18]$. IL-2 is a wellcharacterized cytokine with central roles in inflammation and immune signaling. Moreover, IL-2 is required for the proliferation of $\mathrm{T}$ cells and can stimulate $\mathrm{B}$ cells and natural killer cells [19-21].

IFN $\gamma$ is also a key mediator of inflammatory responses $[22,23]$. IFN $\gamma$ expression in lymphoid tissues is associated with the induction of the IFN $\gamma$-inducible chemokines Mig/CXCL9 and IP-10/CXCL10. It has been proposed that the continuous secretion of these chemokines results in increased inflammation and promotes disease progression [24]. In addition to the ELISA assays that showed inhibition in cytokine secretion, the cells were also cultured with different concentrations of the two compounds (0.45, 0.9, 1.8, 3.6, 5.4 and $10.8 \mu \mathrm{M}$ ) to determined $\mathrm{EC}_{50}$. Cytokine secretion levels were measured against the positive control, PBMC treated with LPS or PMA, and the $\mathrm{EC}_{50}$ values were calculated (Table 1). Treating the cells with either Tomentosin or Inuviscolide resulted in a dose-dependent inhibition of cytokine secretion. The results showed that the $\mathrm{EC}_{50}$ value of both compounds for affecting IL1 $\beta$ is below $0.9 \mu \mathrm{M}$. The $\mathrm{EC}_{50}$ value of both compounds for affecting IL2 is around $0.9 \mu \mathrm{M}$, and the $\mathrm{EC}_{50}$ value of both compounds for affecting IFN $\gamma$ is slightly above1.8 $\mu \mathrm{M}$. These results emphasize the huge effect of both compounds in the reduction of cytokine secretion at low and non cytotoxic concentrations.

Table 1. $\mathbf{E C}_{50}$ Values of Tomentosin and Inuviscolide for Inhibition of Cytokine Secretion from Human PBMC

\begin{tabular}{|c|c|c|}
\hline \multirow{2}{*}{ Cytokine } & \multicolumn{2}{|c|}{$\mathbf{E C}_{\mathbf{5 0}}(\mu \mathbf{M})$} \\
\cline { 2 - 3 } & Inuviscolide & Tomentosin \\
\hline \hline IL1 $\beta$ & $0.4 \pm 0.1$ & $0.5 \pm 0.2$ \\
\hline IFN $\gamma$ & $2.6 \pm 0.4$ & $2.2 \pm 0.5$ \\
\hline IL2 & $1.0 \pm 0.8$ & $0.7 \pm 0.8$ \\
\hline
\end{tabular}

with Inuviscolide and Tomentosin at several concentrations and in parallel with LPS for the induction of IL-1 $\beta$ and IFN $\gamma$, or with phorbol myristate acetate (PMA) and ionomycin for IL2 induction. The relative cytokine secretion levels were assayed in the supernatants by ELISA and $\mathrm{EC}_{50}$ values were calculated (see Materials and Methodology). Data represent $\mathrm{EC}_{50}$ mean values $+/-$ S.D. from four different experiments.

Testing both compounds at a wider range of doses including higher concentrations, showed a decrease in cytokine secretion of IFN $\gamma$, IL1 $\beta$ and IL2 reaching up to
$90 \%$ reduction compared to the positive control (LPS + induced PBMC cells) at a dose between $1.8 \mu \mathrm{M}$ and $3.6 \mu \mathrm{M}$ (data not shown).

Yet, the linear response of cytokine secretion was lost at the higher concentrations. Therefore we preferred to indicate the results obtain with the lowest concentrations, 0.9 and 1.8 $\mu \mathrm{M}$ that still showed a significant reduction in a linear fashion.

Two other cytokines that were measured were IL-6 and TNF $\alpha$ (Fig. 3). IL-6 secretion was not affected by the two compounds, while TNFa level was slightly induced (up to 20\%) (Fig. 3). The elevation in TNF $\alpha$ was not statistically significant, and does not seem to have any biological importance in our model system, since cytotoxicity was not observed, and no signs of stress or death could be detected. Furthermore, higher concentrations of Inv and Tom didn't show an effect on IL6 and TNF $\alpha$, But inconsistency in secretion (small reductions or elevations that were statistically non significant). One possible explanation for the lack of effect of Tom and Inv on those two cytokines could be the fact that IL- 6 and TNF $\alpha$ are subjected to various additional modalities of regulation besides $\mathrm{NF} \kappa \mathrm{B}$, which might overcome the inhibitory effect caused by reduced level of $\mathrm{NF \kappa B}[25,26]$. Another reason is the complexity in regulatory networks that govern proinflammatory cytokine secretion upon specific stimulation, which might contribute to the different effect of the various cytokines tested. Thus, our results indicate that those two compounds have a selective effect on several key proinflammatory cytokines.

Besides the cytokines that were mentioned above, we also tested a few counter regulatory cytokines including IL10 , and they were also down regulated (data not shown). Taking into account the complexity of cytokine regulation that creates different effect for different cytokines and due to the fact, that those counter regulatory cytokines are also target genes of NFKB these results were clear. Furthermore, the detailed mechanism controlling the specificity of these compounds and their activity is still not fully known; thus, the specificity that distinguishes the effect between different cytokines is not yet understood.

\section{Decreased Levels of NFKB and STAT1 Induced by Inuviscolide and Tomentosin}

To further investigate downregulation in the secretion of the three cytokines, IL-1 $\beta$, IL- 2 , and IFN $\gamma$, and to gain a better understanding of the mechanism of action of Tom and
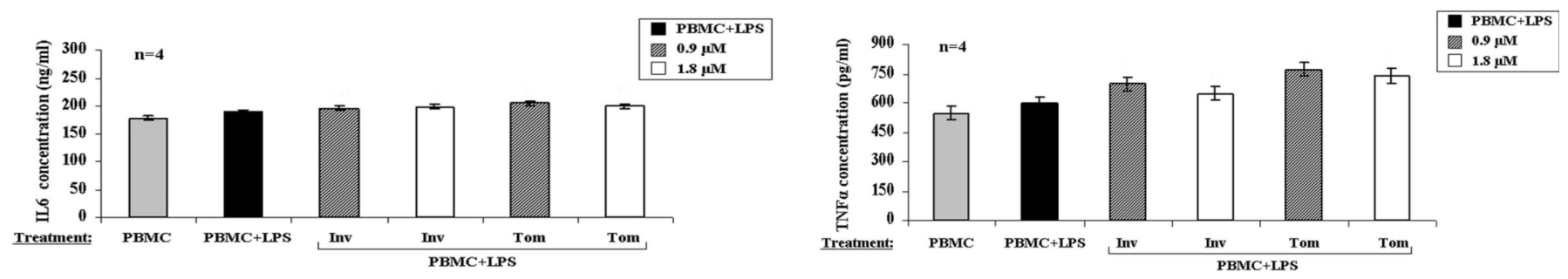

Fig. (3). Effect of Inuviscolide and Tomentosin on IL6 and TNFa secretion levels by human PBMCs in the presence of LPS. PBMC cells were incubated for $24 \mathrm{~h}$ with Inuviscolide and Tomentosin and, in parallel, with $20 \mathrm{ng} / \mathrm{ml} \mathrm{LPS}$ for the induction of IL-1 $\beta$ and IFN $\gamma$, or 1 $\mu \mathrm{g} / \mathrm{ml}$ phorbol myristate acetate (PMA) and $0.5 \mu \mathrm{g} / \mathrm{ml}$ ionomycin for IL2 induction. The relative cytokine secretion levels were assayed in the supernatants by ELISA $(n=4)$. 
Inv, we next analyzed their effect on NF kappa B expression. The rationale for choosing this transcription factor is based on two considerations. First, in our previous study, we showed an inhibitory effect of Inuviscolide on the expression level of nuclear factor kappa B (NFאB). Secondly, those three cytokines are upregulated by $\mathrm{NF \kappa B}[27,28]$. We, therefore, tested whether $\mathrm{NF \kappa B}$ is the target protein that mediates the influence of Inv and Tom in this model. As shown in (Fig. 4A, B), both Inv and Tom downregulated the level of the NFKB component p65/RelA in a dose-dependent manner as demonstrated in column 3 (control) vs columns 5 and 7 (treatment), while they did not affect the protein level of the NF $\kappa$ B components, p50, STAT3, or E2F1. These three proteins were examined in order to verify the specificity of Inv and Tom towards proteins that are directly involved in the cascade of regulation and secretion of the proinflammatory cytokines IL1 $\beta$, IL2, and IFN gamma. The inhibition of NFKB was clearly evident at the concentration of $1.8 \mu \mathrm{M}$, and a slight effect was noted at $0.9 \mu \mathrm{M}$ (which is only half of the effective dose), while the reduction in cytokine secretion was already pronounced at $0.9 \mu \mathrm{M}$. This discrepancy in effective doses could be due to the fact that $\mathrm{NF} \kappa \mathrm{B}$ is a transcription factor, and a small change in its cellular concentration (barely detectable by western blot), could have a great impact on the transcription of specific target genes, such as the three cytokines mentioned above. Another explanation is the lower sensitivity of western analysis in comparison to ELISA tests; therefore NFKB may be reduced at the low compounds concentration, though this reduction is not obvious on the western blots and initiate a cascade of events resulting less production of some inflammatory cytokines that has already seen at the lower concentration. The expression level of another transcription factor, signal transducer and activator of transcription (STAT1), was also tested. STAT1 expression is known to be regulated by IFN $\gamma$ [29] and since IFN $\gamma$ was decreased in our system, we were interested in investigating the fate of this protein, as well. As can be seen in Fig. (4A, B), the expression level of STAT1 was also reduced by both compounds, as demonstrated in column 3 (control) vs columns 5 and 7 (treatment). This result is interesting in light of the published literature showing that STAT1 is one of the key transcription factors that participates in the inflammatory process by being affected through a wide variety of factors, including cytokines, growth hormones, and interferons [30, 31].

Next, we attempted to examine the mechanism through which these two transcription factors were downregulated in our system. It has been shown that NFKB components p65/RelA and STAT1 are downregulated by proteosomal degradation $[32,33]$; therefore, we studied their effect in the presence of a proteosomal inhibitor. As shown in Fig. (4A, B), the protein level of NFKB components p65 and STAT1 was restored in the presence of the proteosomal inhibitor, MG-132 (Fig. 4A, columns 6 and 8 (treatment)). Since STAT1 is also up regulated by Interferon $\gamma$ [29], we suggest that STAT1 might be downregulated by two different mechanisms, by the proteosomal pathway and by inhibition of IFN $\gamma$ production.

Although we provide evidence that showed that the protein level of NFKB component p65 and STAT1 was restored in the presence of the proteosomal inhibitor, we did not test cytokine levels in the presence of the proteosomal inhibitor. $\mathrm{NF \kappa B}$ is negatively regulated by $\mathrm{IkB}$, which will remain active in the presence of the proteosomal inhibitor, and will prevent the transcription factor activity of NFKB. As a result, the level of cytokines that are NFKB target genes will remain down regulated and are not expected to be restored even in the presence of proteosome inhibitors.

Taken together, these results demonstrate that Inv and Tom induced the downregulation of two key transcription factors, NFKB and STAT1 that participate in the inflammation cascade, through proteosomal degradation.

\section{Nontoxic Effect of Inv and Tom on PBMCs}

Finally, we tested the toxicity of two concentrations of Inv and Tom $(0.9$ and $1.8 \mu \mathrm{M})$ in a model of human PBMC cells. In order to examine the toxicity of these two compounds, we incubated the cells with three escalating concentrations $(0.8,1.9,3.8 \mu \mathrm{M})$ of Inv and Tom, in comparison to untreated cells (control), for $24 \mathrm{~h}$, and then performed a cell viability assay (XTT). The results, as presented in Fig. (5), showed no cell toxicity even at the highest concentration of $3.8 \mu \mathrm{M}$. These results are compatible with the previous study, which showed that 20fold higher $(36 \mu \mathrm{M})$ concentrations of Inv and Tom were nontoxic to NIH/3T3 cells [34]. We conclude that the effective concentration on cytokine secretion is far from the toxic dose for these two compounds.

\section{DISCUSSION}

PBMC resembling primary culture is considered to be the best in vitro model for studying the immunomodulatory properties of plant compounds. In the current study, we demonstrate that Inuviscolide and Tomentosin originally purified from the leaves of the Inula viscosa plant inhibited the secretion of the pro-inflammatory cytokines IL-1 $\beta$, IL-2, and IFN $\gamma$, and caused downregulation of two key transcription factors, STAT1 and the p65/RelA subunit of $\mathrm{NF} \kappa \mathrm{B}$, through proteosomal degradation (Fig. 6). A number of plant extracts and natural compounds have been shown to possess an anti-inflammatory effect. In this study, the uniqueness of the two purified compounds are the low concentrations, $0.9 \mu \mathrm{M}$ and $1.8 \mu \mathrm{M}$, at which they mediate a significant effect, up to $80 \%$ reduction in cytokine secretion. Other plant-derived compounds, for example, crude extracts of Ocimum bacilicum [35] in a similar system of induced PBMCs, have been shown to cause around $80 \%$ reduction of pro-inflammatory cytokine at a higher concentration of $30 \mu \mathrm{g} / \mathrm{ml}$ and after incubation of $72 \mathrm{~h}$ with the test compounds. Another example was a comparative analysis of crude extract and pure compound of the plant Boswellia serrata in the same system of induced PBMCs that have been shown to cause around $80 \%$ inhibitory activity of proinflammatory cytokines, again at a higher concentration of $30 \mu \mathrm{g} / \mathrm{ml}$ of the crude extract and $20 \mu \mathrm{g} / \mathrm{ml}$ of the test compound after incubation of $72 \mathrm{~h} \mathrm{[10]}$. These two examples emphasize the potency of our test compounds to reduce proinflammatory cytokines in the system of induced PBMCs already after $24 \mathrm{~h}$ and at a very low concentration. It has been reported that three proteins - PIN-1, PDLIM2, and TMF/ARA160 - direct the degradation of p65/RelA and terminate NFKB activity $[32,36,37]$. The three cytokines, 

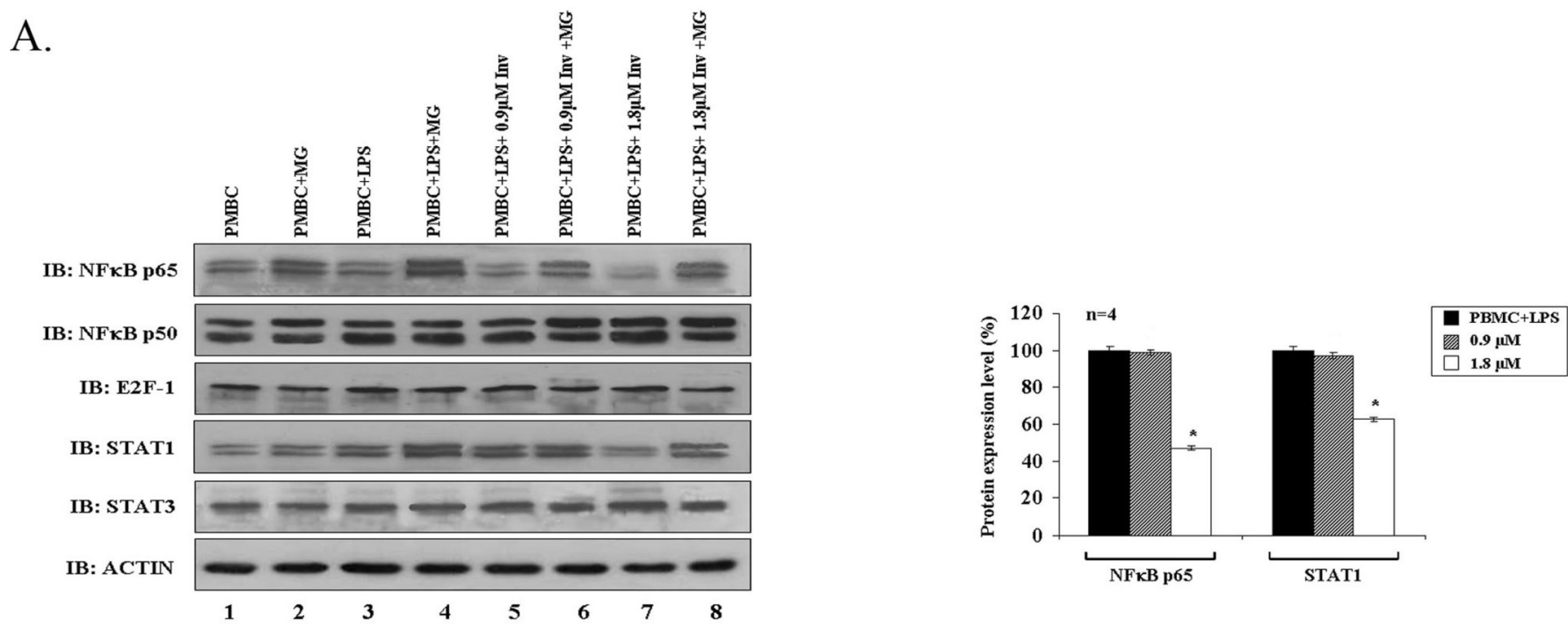

B.
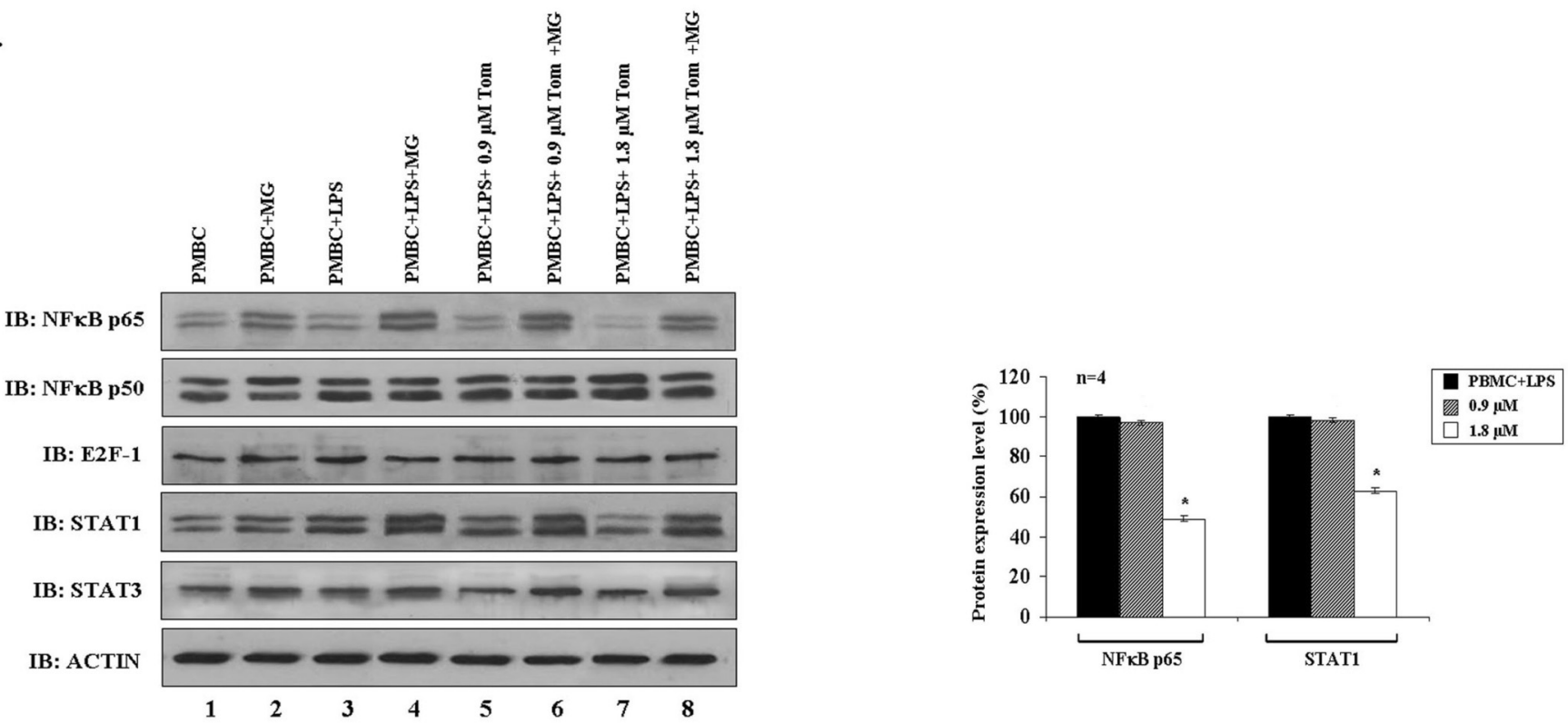

Fig. (4). Reduced levels of p65/RelA and STAT1 in PBMC. PBMCs were incubated for $24 \mathrm{~h}$ with Inuviscolide and Tomentosin and, in parallel, with $20 \mathrm{ng} / \mathrm{ml}$ LPS or $1 \mu \mathrm{g} / \mathrm{ml}$ phorbol myristate acetate (PMA) and $0.5 \mu \mathrm{g} / \mathrm{ml}$ ionomycin. Proteosomal inhibitor (MG-132) was added to designated samples at a final concentration of $3 \mu \mathrm{M}$ for the last $4 \mathrm{~h}$ of incubation. As a control, the same amount of Dimethyl Sulfoxide (DMSO) was added to the samples. (A) Relative levels of NFkB subunits and STAT1 in PBMCs treated with Inuviscolide. Lysates of PBMCs were resolved on 10\% SDS-PAGE and then reacted with anti-p65, anti-p50, anti-E2F1, anti-STAT1, and anti-STAT3 antibodies, in a western blot analysis. For quantification of protein levels, each sample was normalized to the corresponding actin expression level. The Student's t test was used to determine significance of results: ${ }^{*} P<0.05$ when compared with that of the control: PBMC+LPS $(n=4)$. (B) Relative levels of NFKB subunits and STAT1 in PBMCs treated with Tomentosin. Lysates of PBMCs were resolved on 10\% SDSPAGE and then reacted with anti-p65, anti-p50, anti-E2F1, anti-STAT1, and anti-STAT3 antibodies, in a western blot analysis. For quantification of proteins levels, each sample was normalized to the corresponding actin expression level. The Student's $t$ test was used to determine significance of results: $* P<0.05$ when compared with that of the control: PBMC $+\mathrm{LPS}(\mathrm{n}=4)$.

IL-1 $\beta$, IL-2, and IFN $\gamma$, are known to be controlled by the transcription factor NFKB $[27,28]$; therefore, the profound effect of Tom and Inv on p65/RelA can partially explain the reduction of the secretion of these cytokines.

The mechanism by which Inuviscolide and Tomentosin induce proteolytic degradation of p65/relA and STAT1, is still an enigma. The expression level of the transcription factor STAT1 can also be affected by IFN $\gamma$; therefore,
STAT1 can be subjected to down regulation by two different routes, by proteosomal degradation and also by the decreased secretion level of the cytokine IFN $\gamma$ (Fig. 6). The induction of enhanced proteosomal degradation of p65/RelA and STAT1 by Inuviscolide and Tomentosin has not been previously reported, and provides a new understanding of the previously described anti-inflammatory benefits of extracts from the Inula viscosa plant [2]. In this article, we did not 
address STAT1 phosphorylation and p65 nuclear translocation, since Tom and Inv reduce the protein level in a proteosome-mediated manner, and the results clearly showed a reduction in cytokine secretion. We therefore assume that reduction in STAT1 and p65 production would lead to a reduction in their active form, as well. Another issued that should be highlighted is the fact that it has been already been shown that Sesquiterpene Lactones can inhibit NFKB DNA binding by directly alkylating the p65 sub unit [38, 39]. In a future study, this issue will be addressed by performing more specific tests such as chromatin immuno-precipitation to demonstrate reduced occupation of pro-inflammatory cytokines promotors by NFKB.

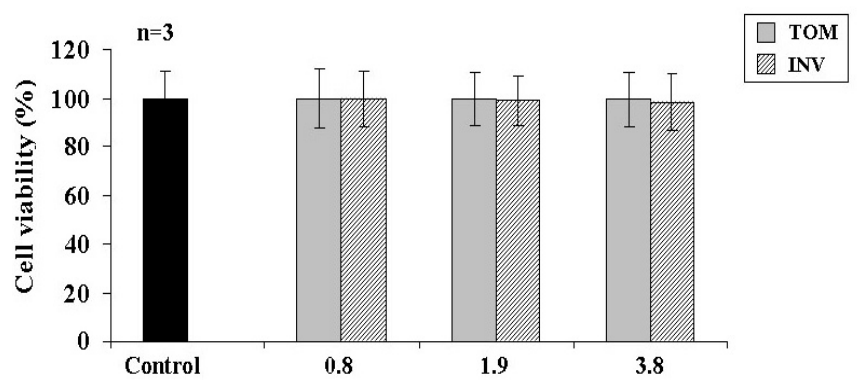

Fig. (5). Effect of Inuviscolide and Tomentosin on PBMC-cell viability. PBMC cells were incubated for $24 \mathrm{~h}$ with the indicated concentrations of Inv and Tom. Cell viability, compared to untreated cells (control), was determined using XTT assay ( $n=3)$.

\section{Inuviscolide and Tomentosin}

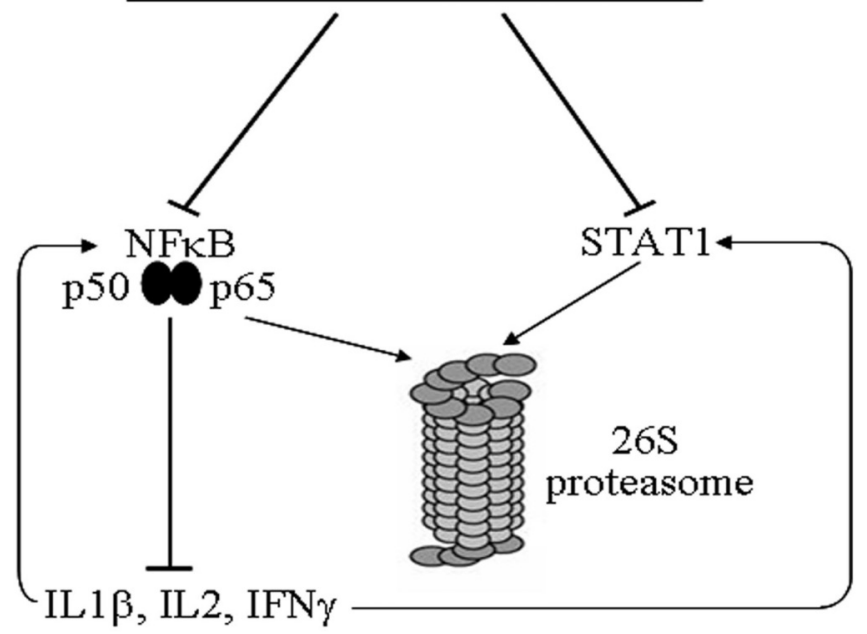

Fig. (6). Proposed mechanism for the anti-inflammatory activity of Inuviscolide and Tomentosin in a model of PBMCs stimulated by LPS or PMA. Inuviscolide and Tomentosin reduce both NFKB p65 and STAT1 protein level through proteasomal degradation. This effect negatively regulates the secretion of the pro-inflammatory cytokine IL $1 \beta$, IL2 and IFN $\gamma$ from PBMC upon stimulation with LPS. In addition, downregulation of IL1 $\beta$ and IFN $\gamma$ can itself inhibit the transcription of NFKB and STAT1 genes, respectively, creating a negative feedback circuit that is selfsustaining and may contribute to the anti-inflammatory activities attributed to this plant.

One of the consequences of our reported results is the possible reduction of the inflammatory reaction by these compounds in cases where the central regulators of the pathologic situation are mediated by IL-1, IL-2, and IFN $\gamma$. Although NFKB participates in the production of a wide range of cytokines, not every cytokine is equally affected by reduction in $\mathrm{NF \kappa B}$ protein levels [32, 36, 37], and this distinction may explain the mechanism of specificity for the activity of these compounds.

Inflammation causes elevated levels of ROS, which harms cells and can promote cancer development [40]. Moreover, the development of malignant changes in association with chronic inflammation has long been recognized in several clinical conditions and is supported by animal tumor models [41-43]. In this regard, plant extract may serve as a prophylactic agent for malignancies in which chronic inflammation, supported by pro-inflammatory cytokines, precede tumor appearance. Angiogenesis and metastasis formation are also influenced by proinflammatory cytokines such as IL-1 $\beta$ [44]. It has been shown that microenvironmental IL- $1 \beta$ and, to a lesser extent, IL- $1 \alpha$ are required for in-vivo angiogenesis and invasiveness of different tumor cells [44]. In another study, IL-1 was the predominant inducer of IL-8 a putative regulator of angiogenesis. Because IL-1 is present in the prostate cancer tumor microenvironment, it is likely that differential regulation of angiogenic factors also occurs in human prostate cancer and contributes to differential tumor growth and metastasis [45]. Therefore, these compounds may also be of help in the reduction of these pathological processes.

Chronic inflammations are associated with malignancies, and it is important to prevent inflammation-mediated neoplastic formation, promotion and/or progression. The association between chronic inflammation and several pathologies, including cancer, has been already demonstrated in previous studies. In the recent years, NFKB has become a key target for the development of new anti-inflammatory and anti-cancer drugs. In this respect, our findings suggest these two compounds, Inuviscolide and Tomentosin, as potential candidates for the development of new anti-inflammatory drugs, as they are nontoxic to normal cells, effective at low concentrations, and target NFKB and STAT1. The medicinal potential of these agents as anti-inflammatory and anticancer agents should be comprehensively investigated in future studies.

\section{ACKNOWLEDGEMENT}

This work was partly supported by the Vinograd Foundation and the Lewitt-Schwartz Chair.

\section{REFERENCES}

[1] Máñez, S.; Recio, M.C.; Gil, I.; Gomez, C.; Giner, R.M.; Waterman, P.G.; Rios, J.L. A glycosyl analogue of diacylglycerol and other antiinflammatory constituents from Inula viscosa. J. Nat. Prod., 1999, 62, 601-604.

[2] Hernandez, V.; del Carmen Recio, M.; Manez, S.; Prieto, J.M.; Giner, R.M.; Rios, J.L. A mechanistic approach to the in vivo antiinflammatory activity of sesquiterpenoid compounds isolated from Inula viscosa. Planta Med., 2001, 67, 726-731.

[3] Calou, I.B.F.; Sousa, D.I.M.; Cunha, G.M.D.; Brito, G.A.D.; Silveira, E.R.; Rao, V.S.; Santos, F.A. Topically applied diterpenoids from Egletes viscosa (Asteraceae) attenuate the dermal inflammation in mouse ear induced by tetradecanoylphorbol 13-acetate- and oxazolone. Biol. Pharm. Bull., 2008, 31, 1511-1516.

[4] Máñez, S.; Hernández, V.; Giner, R.M.; Rios, J.L.; Recio, M.D. Inhibition of pro-inflammatory enzymes by inuviscolide, a sesquiterpene lactone from Inula viscosa. Fitoterapia, 2007, 78, 329-331. 
[5] Khan, A.L.; Hussain, J.; Hamayun, M.; Gilani, S.A.; Ahmad, S.; Rehman, G.; Kim, Y.H.; Kang, S.M.; Lee, I.J. Secondary metabolites from Inula britannica L. and their biological activities. Molecules, 2010, 15, 1562-1577.

[6] Hernandez, V.; Manez, S.; Recio, M.C.; Giner, R.M.; Rios, J.L. Anti-inflammatory profile of dehydrocostic acid, a novel sesquiterpene acid with a pharmacophoric conjugated diene. Eur. J. Pharm. Sci., 2005, 26, 162-169.

[7] Rozenblat, S.; Grossman, S.; Bergman, M.; Gottlieb, H.; Cohen, Y.; Dovrat, S. Induction of $\mathrm{G}(2) / \mathrm{M}$ arrest and apoptosis by sesquiterpene lactones in human melanoma cell lines. Biochem. Pharm., 2008, 75, 369-382.

[8] Bakshi, S.; Bergman, M.; Dovrat, S.; Grossman, S. Unique natural antioxidants (NAOs) and derived purified components inhibit cell cycle progression by downregulation of ppRb and E2F in human PC3 prostate cancer cells. FEBS Lett., 2004, 573, 31-37.

[9] Gilmore, T.D. Introduction to NF-kappa B: players, pathways, perspectives. Oncogene, 2006, 25, 6680-6684.

[10] Gayathri, B.; Manjula, N.; Vinaykumar, K.S.; Lakshmi, B.S.; Balakrishnan, A. Pure compound from Boswellia serrata extract exhibits anti-inflammatory property in human PBMCs and mouse macrophages through inhibition of TNF alpha, IL-1 beta, NO and MAP kinases. Int. Immunopharmacol., 2007, 7, 473-482.

[11] Soboslay, P.T.; Hamm, D.M.; Pfafflin, F.; Fendt, J.; Banla, M.; Schulz-Key, H. Cytokine and chemokine responses in patients coinfected with Entamoeba histolytica/dispar, Necator americanus and Mansonella perstans and changes after anti-parasite treatment. Microb. Infect., 2006, 8, 238-247.

[12] Konig, B.; Streckert, H.J.; Krusat, T.; Konig, W. Respiratory syncytial virus G-protein modulates cytokine release from human peripheral blood mononuclear cells. J. Leuk. Biol., 1996, 59, 403406.

[13] Jager, L.; Merk, H. Arzneimittel-Allergie; Gustav Fischer Verlag: Jena, 1996.

[14] O'Bryan, M.K.; Schlatt, S.; Phillips, D.J.; de Kretser, D.M.; Hedger, M.P. Bacterial lipopolysaccharide-induced inflammation compromises testicular function at multiple levels in vivo. Endocrinology, 2000, 141, 238-246.

[15] Bessler, H.; Salman, H.; Bergman, M.; Alcalay, Y.; Djaldetti, M. In vitro effect of lycopene on cytokine production by human peripheral blood mononuclear cells. Immunol. Invest., 2008, 37, 183-190.

[16] Yardeni, I.Z.; Beilin, B.; Mayburd, E.; Alcalay, Y.; Bessler, H. Relationship between fentanyl dosage and immune function in the postoperative period. J. Opioid Manage., 2008, 4, 27-33.

[17] Song, X.P.; Voronov, E.; Dvorkin, T.; Fima, E.; Cagnano, E.; Benharroch, D.; Shendler, Y.; Bjorkdahl, O.; Segal, S.; Dinarello, C.A.; Apte, R.N. Differential effects of IL-1 alpha and IL-1 beta on tumorigenicity patterns and invasiveness. J. Immunol., 2003, 171, 6448-6456.

[18] Song, X.P.; Krelin, Y.; Dvorkin, T.; Bjorkdahl, O.; Segal, S.; Dinarello, C.A.; Voronov, E.; Apte, R.N. CD11b $(+) / \mathrm{Gr}-1(+)$ immature myeloid cells mediate suppression of $\mathrm{T}$ cells in mice bearing tumors of IL-1 beta-secreting cells. J. Immunol., 2005, 175 , 8200-8208.

[19] Moretta, A.; Accolla, R.S.; Cerottini, J.C. Il-2-mediated T-cell proliferation in humans is blocked by a monoclonal-antibody directed against monomorphic determinants of HLA-DR antigens. J. Exp. Med., 1982, 155, 599-604.

[20] Mehrotra, P.T.; Donnelly, R.P.; Wong, S.; Kanegane, H.; Geremew, A.; Mostowski, H.S.; Furuke, K.; Siegel, J.P.; Bloom, E.T. Production of IL-10 by human natural killer cells stimulated with IL-2 and/or IL-12. J. Immunol., 1998, 160, 2637-2644.

[21] Suzuki, K.; Setoyama, Y.; Yoshimoto, K.; Tsuzaka, K.; Abe, T.; Takeuchi, T. Effect of interleukin-2 on synthesis of B cell activating factor belonging to the tumor necrosis factor family (BAFF) in human peripheral blood mononuclear cells. Cytokine, 2008, 44, 44-48.

[22] Farrar, M.A.; Schreiber, R.D. The molecular cell biology of interferon-gamma and its receptor. Ann. Rev. Immunol., 1993, 11, 571-611.

[23] Billiau, A. [Interferon-gamma, the TH1/TH2 paradigm in autoimmunity]. Bull. Mem. Acad. R. Med. Belg., 1998, 153, 231233 .
[24] Reinhart, T.A.; Fallert, B.A.; Pfeifer, M.E.; Sanghavi, S.; Capuano, S.; Rajakumar, P.; Murphey-Corb, M.; Day, R.; Fuller, C.L.; Schaefer, T.M. Increased expression of the inflammatory chemokine CXC chemokine ligand 9/monokine induced by interferon-gamma in lymphoid tissues of rhesus macaques during simian immunodeficiency virus infection and acquired immunodeficiency syndrome. Blood, 2002, 99, 3119-3128.

[25] Hershko, D.D.; Robb, B.W.; Luo, G.J.; Hasselgren, P.O. Multiple transcription factors regulating the IL-6 gene are activated by cAMP in cultured Caco-2 cells. Am. J. Physiol. Regul. Integr. Comp. Physiol., 2002, 283, R1140-R1148.

[26] Myokai, F.; Takashiba, S.; Lebo, R.; Amar, S. A novel lipopolysaccharide-induced transcription factor regulating tumor necrosis factor alpha gene expression: Molecular cloning, sequencing, characterization, and chromosomal assignment. Proc. Natl. Acad. Sci. USA, 1999, 96, 4518-4523.

[27] Hiscott, J.; Marois, J.; Garoufalis, J.; Daddario, M.; Roulston, A.; Kwan, I.; Pepin, N.; Lacoste, J.; Nguyen, H.; Bensi, G.; Fenton, M. Characterization of a functional Nf-kappa-B Site in the human interleukin-1-beta promoter - evidence for a positive autoregulatory loop. Mol. Cell Biol., 1993, 13, 6231-6240.

[28] McCaffrey, P.G.; Jain, J.; Jamieson, C.; Sen, R.; Rao, A. A T-cell nuclear factor resembling Nf-at binds to an Nf-kappa-B site and to the conserved lymphokine promoter sequence Cytokine-1. J. Biol. Chem., 1992, 267, 1864-1871.

[29] Lehtonen, A.; Matikainen, S.; Julkunen, I. Interferons up-regulate STAT1, STAT2, and IRF family transcription factor gene expression in human peripheral blood mononuclear cells and macrophages. J. Immunol., 1997, 159, 794-803.

[30] Silva, C.M.; Lu, H.W.; Weber, M.J.; Thorner, M.O. Differential tyrosine phosphorylation of Jak1, Jak2, and Stat1 by growthhormone and interferon-gamma in IM-9 cells. J. Biol. Chem., 1994, 269, 27532-27539.

[31] Gimeno, R.; Lee, C.K.; Schindler, C.; Levy, D.E. Stat1 and Stat2 but not Stat 3 arbitrate contradictory growth signals elicited by alpha/beta interferon in T lymphocytes. Mol. Cell Biol., 2005, 25, 5456-5465.

[32] Abrham, G.; Volpe, M.; Shpungin, S.; Nir, U. TMF/ARA160 downregulates proangiogenic genes and attenuates the progression of PC3 xenografts. Int. J. Cancer, 2009, 125, 43-53.

[33] Yokosawa, N.; Yokota, S.; Kubota, T.; Fujii, N. C-terminal region of STAT-1 alpha is not necessary for its ubiquitination and degradation caused by mumps virus $\mathrm{V}$ protein. J. Virol., 2002, 76, 12683-12690.

[34] Rozenblat, S. Anti-cancer activity of Inula viscosa on melanoma cells. PhD thesis. Ramat-Gan: Bar-Ilan University, 2006.

[35] Selvakkumar, C.; Gayathri, B.; Vinaykumar, K.S.; Lakshmi, B.S.; Balakrishnan, A. Potential anti-inflammatory properties of crude alcoholic extract of Ocimum basilicum L. in human peripheral blood mononuclear cells. J. Health Sci., 2007, 53, 500-505.

[36] Ryo, A.; Suizu, F.; Yoshida, Y.; Perrem, K.; Liou, Y.C.; Wulf, G.; Rottapel, R.; Yamaoka, S.; Lu, K.P. Regulation of NF-kappa B signaling by Pin1-dependent prolyl isomerization and ubiquitinmediated proteolysis of p65/RelA. Mol. Cell, 2003, 12, 1413-1426.

[37] Tanaka, T.; Grusby, M.J.; Kaisho, T. PDLIM2-mediated termination of transcription factor NF-kappa B activation by intranuclear sequestration and degradation of the p65 subunit. Nat. Immunol., 2007, 8, 584-591.

[38] García-Piñeres, A.J.; Castro, V.; Mora, G.; Schmidt, T.J.; Strunck, E.; Pahl, H.L.; Merfort, I. Cysteine 38 in p65/NF-kappaB plays a crucial role in DNA binding inhibition by sesquiterpene lactones. $J$. Biol. Chem., 2001, 276, 39713-39720.

[39] Ly $\beta$, G.; Knorre, A.; Schmidt, T.J.; Pahl, H.L.; Merfort, I. The anti-inflammatory sesquiterpene lactone helenalin inhibits the transcription factor NF-kappa B by directly targeting p65. J. Biol. Chem., 1998, 273, 33508-33516.

[40] Azad, N.; Rojanasakul, Y.; Vallyathan, V. Inflammation and lung cancer: Roles of reactive oxygen/nitrogen species. J. Toxicol. Environ. Health - Part B - Crit. Rev., 2008, 11, 1-15.

[41] Clevers, H. At the crossroads of inflammation and cancer. Cell, 2004, 118, 671-674.

[42] Balkwill, F.; Charles, K.A.; Mantovani, A. Smoldering and polarized inflammation in the initiation and promotion of malignant disease. Cancer Cell, 2005, 7, 211-217. 
[43] Coussens, L.M.; Werb, Z. Inflammatory cells and cancer: Think different! J. Exp. Med., 2001, 193, F23-F26.

[44] Voronov, E.; Shouval, D.S.; Krelin, Y.; Cagnano, E.; Benharroch, D.; Iwakura, Y.; Dinarello, C.A.; Apte, R.N. IL-1 is required for tumor invasiveness and angiogenesis. Proc. Natl. Acad. Sci. USA, 2003, 100, 2645-2650.
[45] Ferrer, F.A.; Miller, L.J.; Andrawis, R.I.; Kurtzman, S.H.; Albertsen, P.C.; Laudone, V.P.; Kreutzer, D.L. Angiogenesis and prostate cancer: in vivo and in vitro expression of angiogenesis factors by prostate cancer cells. Urology, 1998, 51, 161-167.

(C) Abrham et al.; Licensee Bentham Open.

This is an open access article licensed under the terms of the Creative Commons Attribution Non-Commercial License (http://creativecommons.org/licenses/bync/3.0/) which permits unrestricted, non-commercial use, distribution and reproduction in any medium, provided the work is properly cited. 